\title{
A empregabilidade dos egressos do curso de Administração das Faculdades Integradas de Taquara: estudo de caso
}

\author{
Dilani Silveira Bassan ${ }^{1}$ \\ Patricia Fabiane Hahn ${ }^{2}$
}

\section{Resumo}

Esta pesquisa tem a finalidade de analisar da empregabilidade dos egressos do curso de Administração das Faculdades Integradas de Taquara, formados no período 2007-2011, residentes no Vale do Paranhana. Trata-se de uma pesquisa quantitativa, cujos resultados foram analisados em comparativo com habilidades descritas como fundamentais para a empregabilidade e com a média nacional de remuneração para graduados na área. Disserta-se sobre as diversas habilidades de que um bacharel em Administração necessita para um bom desempenho no mercado de trabalho, evidenciando a importância do conhecimento, tanto para os trabalhadores quanto para as empresas que irão usufruir destes, especialmente 0 conhecimento advindo do ensino superior, pois é comprovada sua importância para a obtenção de retorno no mercado de trabalho, porém salienta-se que o diploma de ensino superior em si não satisfaz às exigências para uma boa empregabilidade, mas, sim, a capacidade de aplicação dos conhecimentos adquiridos neste, concomitante com habilidades individuais. Por fim, a pesquisa mostra que os egressos, em sua maioria, apresentam remuneração acima da média nacional e boa qualificação, além de possuírem a capacidade de optar pela forma de emprego, diversificando as empresas em que atuam e, inclusive, mostrando iniciativa de abrir seu próprio negócio.

Palavras-chave: Empregabilidade. Ensino Superior. Mercado de trabalho.

\begin{abstract}
This research has the purpose of analyzing the employability of the graduates of the management course of the Faculdades Integradas de Taquara, graduated between the years of 2007 and 2011, residents in the Vale do Paranhana. This is a quantitative survey, whose results were analyzed in comparison with skills described as fundamental to employability and the average national salary for graduates in the area. Lectures up on the various skills that a degree in Administration needs to perform well in the labor market, highlighting the importance of knowledge, both for workers and for businesses that will take advantage of these, especially the knowledge provided higher education it is proven its importance to obtain feedback on the labor market, however, notes that the higher education degree itself does not meet the requirements for good employability, but the ability to apply knowledge

\footnotetext{
${ }^{1}$ Economista, doutoranda em Desenvolvimento Regional na Universidade de Santa Cruz do Sul UNISC/RS e professora das Faculdades Integradas de Taquara - FACCAT/RS. dilanib@faccat.br ${ }^{2}$ Administradora. patriciahahn@faccat.br.
} 
acquired in this concomitant individual skills. Finally, research shows that the graduates, mostly present remuneration above the national average and good qualification, besides, they have the ability to choose the form of employment, diversifying into businesses that operate and even showing initiative open your own business.

Keywords: Employability. Higher Education. Labor Market.

\section{Introdução}

$\mathrm{Na}$ atualidade, as transformações são constantes e, com elas, surgem necessidades como a busca por informação e conhecimento, especialmente no campo profissional. As empresas, por sua vez, buscam profissionais que detenham bom conhecimento para o desempenho de suas atividades. Dessa forma, o conhecimento tornou-se um recurso econômico relevante, tomando lugar até mesmo à frente da matéria-prima e, às vezes, do dinheiro. Logo, gerenciar e investir em capital humano tende a ser prioritário em uma empresa, pois é ele que irá proporcionar-lhe vantagem competitiva no mercado.

As Faculdades Integradas de Taquara - FACCAT possuem curso noturno de Administração e, nos últimos cinco anos, compreendidos entre 2007 e 2011, formaram, em média, 50 (cinquenta) acadêmicos ao ano, sendo o curso que possui maior número de alunos na Instituição. A FACCAT possui sua sede no Município de Taquara, cidade situada no estado do Rio Grande do Sul e integrante do Vale do Paranhana, onde possui importante papel para o desenvolvimento regional. Nessa perspectiva, o presente trabalho foi realizado com o objetivo de conhecer a empregabilidade dos egressos do curso de Administração das Faculdades Integradas de Taquara, formados no período 2007-2011, residentes no Vale do Paranhana.

Para tanto, realizou-se uma pesquisa utilizando o método dedutivo com abordagem quantitativa, e de caráter exploratório e descritivo. Para a coleta dos dados, utilizou-se a pesquisa bibliográfica de autores que proporcionassem maior entendimento sobre empregabilidade, mercado de trabalho, e a elucidação da função do profissional de Administração. Utilizou-se, também, a aplicação de questionário, entre os meses de agosto e setembro de 2012. 
Para alcançar o objetivo desta pesquisa, procurou-se obter informações que permitissem relacionar as condições salariais dos egressos com base comparativa com o ranking de remuneração apresentado no estudo de Neri (2005), marco referencial deste trabalho. Buscou-se, ainda, levantar informações que possuíssem arrolamento às proposições de Chahad et al. (1998) e de Minarelli (2010) quanto à rotatividade dos trabalhadores no mercado de trabalho e à tendência à abertura do negócio próprio verificado por Oliveira e Piccinini (2012) e proposto por Escrivão Filho (2008).

Por último, procurou-se levantar informações complementares quanto à avaliação do mercado de trabalho do Vale do Paranhana para profissionais bacharéis em Administração, a partir do ponto de vista dos egressos do curso, a verificação da aplicação, ou não, dos conhecimentos adquiridos no Curso de Administração em seu atual trabalho, e a continuidade dada aos estudos pelos acadêmicos através do ingresso em cursos de especialização.

A presente pesquisa justifica-se pela contribuição para o meio acadêmico, pois apresenta o levantamento da inserção dos bacharéis em Administração no mercado de trabalho, mostrando a importância do curso superior de Administração para os futuros profissionais. O estudo traz, ainda, para a sociedade, embasamento para a tomada de decisão quanto à escolha de ingressar no Curso de Administração, para incremento de sua empregabilidade. Por fim, auxiliará a pesquisadora na verificação da situação do mercado de trabalho da região do Vale do Paranhana para bacharéis em Administração, de acordo com a perspectiva dos acadêmicos já formados e residentes na região, onde ela também reside e pretende atuar.

\section{0 curso de Administração e e mercado de trabalho}

As Faculdades Integradas de Taquara (2012), também conhecida como FACCAT, por ter sido originada inicialmente como Faculdade de Ciências Contábeis e Administrativas de Taquara, é conhecida até hoje pela sigla que é utilizada fortemente em seu logotipo para publicidade. A FACCAT é uma Instituição de Ensino Superior conhecida em todo o Brasil, pois se encontra entre as melhores do país 
desde os anos 1990, resultado da qualidade do desempenho dos alunos, dos professores e dos demais colaboradores atuantes na instituição. Conforme informação institucional em seu site, a Instituição iniciou suas atividades em 1970 como uma extensão do Curso de Economia da Universidade do Vale do Rio dos Sinos, vindo a obter sua autonomia como Faculdade de Ciências Contábeis e Administrativas de Taquara somente em 1977, com o reconhecimento de seus primeiros cursos de graduação, Administração e Ciências Contábeis. Atualmente, a Instituição possui 17 cursos de graduação.

Inicialmente, as atividades da FACCAT foram realizadas nas dependências do Colégio Santa Teresinha, situado no centro da cidade de Taquara, de 1970 a 1999, mas, devido ao crescimento do número de alunos, surgiu a necessidade de maior espaço físico. No ano 2000, é constituído seu campus, situado no Bairro Fogão Gaúcho, Rodovia ERS 115, que viabilizou a criação de novos cursos de graduação, atualmente no número de 17 (dezessete). Até 2006, cada curso possuía uma faculdade isolada de acordo com a área de formação, porém, em 2007, a Instituição obteve o reconhecimento como Faculdades Integradas de Taquara.

A Instituição possui sua sede no Município de Taquara, cidade situada no estado do Rio Grande do Sul, que, conforme informação no site da Câmara da Indústria, Comércio e Serviços do Vale do Paranhana, é um dos municípios que compõem o Vale do Paranhana, juntamente com as cidades de Parobé, Igrejinha, Três Coroas, Rolante e Riozinho. De acordo com o último levantamento feito pela Fundação de Economia e Estatística - FEE (2009), o Vale do Paranhana soma uma população de 185.468 habitantes, possui Produto Interno Bruto - PIB superior a dois bilhões de reais e renda per capita média de aproximadamente treze mil reais.

Conforme debate do movimento Agenda Paranhana 2020 (2013), publicado no site do ClicRBS da emissora RBSTV, o Vale do Paranhana possui um diferencial competitivo que é o fato de ter uma visão clara de onde quer chegar em educação, saúde e desenvolvimento regional. No quesito educação, a agenda destacou a importância das Faculdades Integradas de Taquara, reconhecida no país para a formação e qualificação da população do Vale e consequente desenvolvimento regional, uma vez que há uma carência de profissionais qualificados para a demanda do mercado em geral. 
Segundo dados secundários colhidos com a Secretaria da FACCAT, o curso de Administração, foco de estudo deste trabalho, é o que possui maior número de alunos atualmente, logo o que forma maior número de profissionais. Nos últimos cinco anos, compreendidos de 2007 a 2011, formaram-se, em média, 50 (cinquenta) acadêmicos do curso ao ano. Tendo como base o resultado dos anos de 2002 a 2006, com aproximadamente 27 alunos formados por ano, essa média praticamente dobrou nos últimos cinco anos. Por ser um curso noturno, atrai um público específico, alunos que trabalham durante o dia e estudam à noite. Esses acadêmicos tendem a possuir maior habilidade para a empregabilidade. Inclusive, para alguns, a obtenção do diploma universitário auxilia na manutenção do próprio emprego (CAMPOS, 2011).

O Curso de Administração das Faculdades Integradas de Taquara tem por objetivos básicos e gerais fomentar o desenvolvimento da região, especialmente nos setores socioeconômico e cultural, formando profissionais competentes. O site da Instituição destaca, ainda, possuir excelente nível nos cursos de graduação que oferece, uma vez que os profissionais que se formam na FACCAT estão melhor posicionados no mercado de trabalho, fato que comprova a qualidade do ensino. Para tanto, promove ainda cursos de pós-graduação em nível de especialização e de qualificação e de aperfeiçoamento profissional, que, de acordo com Lacombe e Heilborn (2008), são de vital importância para o crescimento da carreira profissional.

\subsection{As organizações e a Administração de empresas}

O funcionamento da sociedade depende das organizações. De acordo com Lacombe e Heilborn (2008), não há como uma única pessoa competir com uma organização, pois essa é constituída por um grupo de pessoas em busca de um objetivo comum, portanto uma organização possui desempenho superior ao de um indivíduo. Para Alonso, López e Castrucci (2006), uma organização é um conjunto de pessoas que trabalham em função de um mesmo fim. $O$ autor frisa que é vital e indispensável, para a sobrevivência e convivência da humanidade, dentro das organizações de pessoas com funções distintas, em atividades produtivas e administrativas, que convivem como um organismo vivo, a troca de informações, 
trabalhando sincronizadamente e unidos em busca da sobrevivência. Ainda de acordo com Alonso, López e Castrucci (2006), apesar de trabalharem em conjunto, os trabalhadores de uma organização são indivíduos com objetivos de autorrealização. Para tanto, as empresas precisam proporcionar espaço e oportunidade de crescimento para o indivíduo para que ele alcance formas de autorrealização dentro da empresa, contribuindo, assim, de forma substancial para ela.

Nessa perspectiva, é possível dimensionar a importância das organizações para a sociedade, pois "em geral, as pessoas nascem em hospitais, são educados em escolas e trabalham em uma organização" (LACOMBE; HEILBORN, 2008, p. 13). Cabe mencionar, ainda, que as empresas abrangem tal complexidade de atuação capaz de satisfazer as mais distintas necessidades dos seres humanos, seja no campo emocional, espiritual, intelectual, social, econômico, entre outros (CHIAVENATO, 2008).

Atentando para o fato de que uma organização muito racional acaba por mecanizar seus participantes, não os envolvendo no entendimento do todo, Chiavenato (2008) afirma que a empresa deve saber mediar seus métodos e processos e levar em conta o capital humano. Para tal, necessita incrementar esse capital para que seja possível a aplicação de conhecimento acerca de novos produtos, serviços, processos internos, inovação, entre outros.

De acordo com Lacombe e Heilborn (2008), uma organização pode ser descrita como o processo de organizar, logo, como é possível acompanhar na figura 2, uma organização requer Administração. Administrar uma instituição envolve enorme número de variáveis, dentre elas, porte e complexidade da organização, julgamento humano, ambiente externo, políticas, métodos, entre muitas outras. Dessa forma, Lacombe e Heilborn (2008) atentam para o fato de que a Administração não é uma ciência exata, pois não existem fórmulas prontas para a obtenção dos resultados desejados: é necessário conhecimento para a complexa análise das variáveis em questão.

Para Chiavenato (2008), as empresas possuem relações dinâmicas em constante alteração com seus participantes na busca por atender às exigências que Ihes são impostas, tanto pelo ambiente externo quanto pelo ambiente interno. Nessa linha de raciocínio, Casas et al. (1999) mencionam que, com a globalização, as 
estruturas empresariais tendem a ser constantes, sempre adaptando-se às mudanças, porém avalia que essas serão cada vez mais enxutas, pois, com a acessibilidade à informação e com as transformações tecnológicas, necessitam cada vez mais qualidade do que quantidade em seus recursos humanos, logo profissionais com cursos voltados para empresas, como Administração, tornam-se cada vez mais indispensáveis para as organizações.

Conforme Stewart (1998), o conhecimento tornou-se um recurso econômico relevante para as empresas, tomando lugar à frente da matéria-prima e às vezes até mesmo do dinheiro. Para tanto, gerenciar e investir em capital humano deve ser prioritário em uma empresa, pois é ele que irá proporcionar-lhe vantagem competitiva no mercado. Em concordância, Probst, Raub e Romhardt (2002, p. 25) afirmam que "[...] a manutenção cuidadosa dos ativos intelectuais é uma tarefa vital da Administração". Assim, é possível observar a importância do profissional de Administração dentro de uma empresa, neste caso, aquele que trabalha na área de recursos humanos, uma das diversas áreas de atuação deste profissional. A partir da visão desses dois autores, é possível observar que o capital intelectual das empresas já vem se mostrando fundamental desde a década passada e toma magnitude com os passar dos anos.

O administrador não é apenas importante para o funcionamento de uma empresa: ele é obrigatório para todas as empresas, entidades e escritórios técnicos que explorem, sob qualquer forma, as atividades de administrador, devendo este estar devidamente registrado no Conselho Regional de Administração, conforme a Resolução Normativa CFA № 337, de 4 de dezembro de 2006.

\subsection{O profissional bacharel em Administração}

O profissional bacharel em Administração proverá informações para embasar a tomada de decisões da cúpula estratégica de uma organização. Esse profissional deverá determinar a melhor forma e os recursos necessários para a coordenação de equipes em prol do desempenho da empresa, bem como a obtenção de resultados para alcançar os objetivos estabelecidos pela alta direção, conforme Lacombe e 
Heilborn (2008). Para coordenar equipes, o administrador necessitará de habilidades como: boa comunicação, raciocínio lógico, crítico e analítico; iniciativa e capacidade de inovação; visão sistêmica da organização; negociação; liderança.

Ainda de acordo com Lacombe e Heilborn (2008), o profissional de Administração deverá aprender a vida toda, pois o campo é muito vasto e requer diversas habilidades como as citadas anteriormente, que deverão ter constante aprimoramento, uma vez que a Administração possui tal amplitude que possibilita ao profissional atuar em várias áreas dentro de uma empresa. Administrar é algo muito complexo e abrangente: é preciso ir além do conhecimento, buscar e aprimorar habilidades constantemente para dar conta do leque administrativo de uma empresa.

Para Lima (2002), os administradores devem ser responsáveis pelo próprio aprendizado na busca de sua formação profissional e desenvolvimento pessoal, cabendo exclusivamente a eles a busca de novos conhecimentos, pois a educação é um processo constante e atualizar-se é fundamental para a manutenção deste conhecimento. Porém, de nada adianta o administrador possuir conhecimento e não saber aplicá-lo, pois sua aplicação produtiva é que acarretará resultados visíveis, conforme Probst, Raub e Romhardt (2002).

O ensino da Administração é essencial para o profissional no mercado de trabalho, porém Pastore (1998) ressalta que a polivalência é o atributo mais buscado por empresários no mercado de trabalho, pois possibilita aliar conhecimento às mudanças e inovações, além de maior potencial de diversidade de habilidades.

No tocante a inovações, Kohlrausch (2004) versa sobre a importância do acompanhamento das novas tecnologias para a manutenção do profissional no mercado de trabalho, pois o administrador trabalha com processos, e esses são constantemente reformulados através do desenvolvimento de novas tecnologias que buscam aprimorá-los e otimizá-los. Logo, se o administrador não acompanha as transformações dos processos de sua organização, acaba por se tornar obsoleto e dispensável.

O administrador busca a obtenção de resultados através de pessoas, portanto uma habilidade importante para o administrador é a liderança, que pode ser descrita como "[...] a capacidade que algumas pessoas possuem de conseguir que outras, de 
modo espontâneo, ultrapassem o estabelecido formalmente" (FIORELLI, 2003, p. 173). Essa habilidade em especial é a que dará destaque ao profissional de Administração dentro de uma organização. Cabe ressaltar que, conforme Fiorelli (2003), a liderança é algo intrínseco e depende de fatores emocionais e de personalidade. Para Alonso, López e Castrucci (2006), o profissional de Administração pode atuar em qualquer dos níveis gerenciais. Em qualquer posição, - administrador possui inúmeras possibilidades de destacar-se como líder: dependerá apenas de suas condições pessoais. Destaca-se, ainda, que o líder costuma ser empreendedor, fato que lhe fornece subsídios para encabeçar cargos de diretoria ou até mesmo a abertura de um negócio próprio.

Conforme Alonso, López e Castrucci (2006), o indivíduo que estuda Administração costuma ser um empregado diferenciado nas empresas, pois tende a possuir conhecimentos diferenciados dos demais. Se souber aplicá-los, poderá atingir cargos como o de diretor ou executivo de uma empresa, deixando de ser um empregado regido por leis trabalhistas. "[...] os serviços do administrador, seja ele diretor ou empregado, dizem respeito às engrenagens vitais da empresa, as quais ele ordena e organiza." (ALONSO; LÓPEZ; CASTRUCCI, 2006, p. 208). Nessa perspectiva, o autor alerta para a importância da ética nas ações deste profissional, afirmando que a ética está para a Administração como a Administração está para a empresa. Dessa forma, a ética não é obtida através de códigos ou regulamentos, e sim através dos administradores. Alonso, López e Castrucci (2006) não evidenciam a importância da ética por acaso: ela é obrigatória para a execução da atividade da profissão de Administração, e, conforme o Código de Ética Profissional do Administrador, o desacato aos seus deveres implica infração sujeita a julgamento do Tribunal Regional de Ética dos Administradores.

\subsection{Empregabilidade}

Entre os conceitos acerca de empregabilidade definidos por Minarelli (2010), está a capacidade de ser contratável. Nessa mesma linha de pensamento, para Almeida (2006), a empregabilidade é caracterizada pela capacidade de adequação do profissional ao mercado de trabalho, sendo proporcional a sua adaptação ao 
mercado. Para Bandura (1997), a empregabilidade diz respeito à autoeficácia individual e possui relação com a visão que o indivíduo possui de si próprio quanto a sua capacidade de atingir determinado desempenho. Esse autor afirma que não se trata propriamente de se possuir determinadas habilidades, mas da capacidade que o indivíduo possui de visualizar e acreditar em suas habilidades, além de levar em conta o seu esforço, persistência e a capacidade de lidar com emoções perante um obstáculo.

De acordo com Helal e Rocha (2011), os atuais conceitos acerca da empregabilidade transferem a responsabilidade pelo emprego para o próprio trabalhador. Os autores também acrescentam que as empresas, muitas vezes, fazem uso desse conceito como estratégia para se livrarem do fardo da não contratação e da demissão. Essa transferência de responsabilidade para manutenção do mercado de trabalho acaba por tornar os indivíduos cada vez mais competitivos na busca da habilidade de manter-se empregados. Os autores acrescentam ainda que a empregabilidade vai além de qualificação e experiência, depende também da capacidade de socialização do profissional.

Para Minarelli (2010), atualmente não é mais comum um profissional fazer carreira dentro de apenas uma só empresa, pois as organizações estão em modificações constantes devido a exigências da economia global, reformulando com frequência seus cargos. Essas mudanças geram um estímulo para que as pessoas possuam uma formação ampla, que lhes possibilite atuar em diferentes áreas. "É bom lembrar que a carreira pertence ao profissional" (MINARELLI, 2010, p. 9). Nessa perspectiva, atenta-se para o fato de que o empregado não pode colocar sua carreira nas mãos do empregador, devendo buscar aprimorar-se para que possa se garantir em vários tipos de situações e estar preparado no caso de uma possível demissão ou o almejo de um cargo específico. De acordo com Almeida (2006), a competência representa o saber, enquanto a habilidade está relacionada à prática, e a empregabilidade de um profissional deve estar de acordo com sua realidade, com suas verdadeiras habilidades, não sendo suficiente só obter um diploma.

O resultado apontado pelo estudo de Neri (2005), que mostra que indivíduos com mais de uma fonte de emprego são mais bem sucedidos do ponto de vista salarial, vem ao encontro da opinião de Minarelli (2010) quanto ao novo formato de 
empregabilidade, em que, a partir das mudanças globais e consequentes mudanças organizacionais, o emprego fixo não é mais uma forma de segurança como antigamente, pois as empresas se transformam muito rapidamente, e o empregado pode se tornar desnecessário num piscar de olhos. Então, para manter-se no mercado de trabalho atual, é fundamental a busca por formas alternativas de emprego, fato que também auxilia na diversificação de habilidades, contribuindo para a sua manutenção dentro desse mercado.

\section{$2.4 \mathrm{O}$ mercado de trabalho atual}

O termo mercado de trabalho é, até hoje, tema de muitas discussões que buscam conceituá-lo, dimensioná-lo e compreendê-lo. Para Oliveira e Piccinini (2011), esse pode ser analisado, dentre outras formas, como relações entre indivíduos, instituições e sociedade, porém alertam que o conceito de mercado de trabalho deve ser constantemente requestionado, uma vez que a sociedade possui caráter dinâmico. Conforme Chahad et al. (1998), o mercado de trabalho tem relação direta com a economia, uma vez que as variáveis que o determinam, como salário, emprego, rotatividade e produtividade são condicionadas pelo desempenho desta.

Para melhor entendimento da relação economia e mercado de trabalho, entende-se que, quando o desenvolvimento econômico é positivo, os salários sobem, pois mais bens são disponibilizados pelo mercado, que necessita que o trabalhador obtenha maior poder de aquisição, que será adquirido através da recompensa pela alta atividade produtiva da empresa, formando um ciclo. Nessa perspectiva, o crescimento da economia depende do aumento da produtividade das empresas. Esse aumento gera crescimento de emprego e oportunidades de trabalho, o que impulsiona a rotatividade. A rotatividade, por sua vez, ocorre pelo seguinte fato, conforme Chahad et al. (1998, p. 405):

A rotatividade cresce porque, com a ampliação das oportunidades de emprego, os trabalhadores têm maiores chances de mobilidade ocupacional e/ou entre firmas, ou mesmo buscam maior salário na mesma ocupação. [...], os trabalhadores educam-se e treinam-se, tornando-se mais eficientes. 
É possível observar que o desenvolvimento econômico proposto por Chahad, et al. (1998) sugere que o incremento da economia tende à rotatividade e está presente atualmente na visão do mercado de trabalho. Como descreve Minarelli (2010, p. 3), "As relações de trabalho já não são mais duradouras como antigamente". Também adverte que a manutenção dos conhecimentos é necessária para que o trabalhador tenha o poder de escolha de sua forma de emprego. A questão do conhecimento para bom desempenho no mercado de trabalho já era visualizada igualmente por Casas et al. (1999), que, sob a ótica da globalização, afirmam que esta não afeta somente as empresas, mas também os funcionários, que se globalizam através do acesso a informações e que os leva ao entendimento da importância do conhecimento, podendo este ser adquirido de diversas formas.

A expansão do ensino superior traz um grande diferencial no mercado de trabalho atual, pois a existência de pessoas qualificadas instiga as empresas a procurarem por esses profissionais. Porém é importante salientar que, conforme Marques (2009), a obtenção de um diploma não representa garantia de colocação no mercado de trabalho, ao passo que sua ausência minimiza sua capacidade de inserção profissional. Nessa perspectiva, o diploma seria apenas mais um requisito necessário para assegurar a competição, mostrando que o mercado de trabalho, no que diz respeito à escolha do empregador, tende a ficar cada dia mais rigoroso. Cabe ao indivíduo estar atento às exigências e saber combinar sua formação com suas competências e habilidades.

Para Lemos e Pinto (2008), há uma crise contemporânea no mercado de trabalho, que se origina pela falta de qualificação dos trabalhadores e que, na verdade, é compreendida pela existência de grande oferta inadequada de força de trabalho, mais especificamente, falta de capacitação. Assim, um curso superior torna-se uma ótima forma de buscar a inserção no mercado de trabalho, porém podendo ser requerido apenas por sua formação geral, necessitando ainda outras inúmeras formas de capacitação na busca por uma especialização.

\subsection{Empregabilidade e curso de graduação em Administração}


Em um estudo, Campos (2011) buscou a construção de uma escala de empregabilidade em uma amostra com 628 estudantes universitários dos cursos de Administração, Engenharias e Psicologia de instituições públicas e privadas do Estado de São Paulo. Um comparativo entre os cursos verifica que, quanto à preparação para a empregabilidade, de acordo com a formação do acadêmico, os que possuem maior preparo para o mercado de trabalho são Engenharias e Administração, com destaque para as instituições privadas. Para Campos (2011), o resultado pode estar ligado ao fato de que os cursos particulares possuem alunos que, geralmente, estudam de dia e trabalham à noite.

Outro estudo, realizado por Oliveira e Piccinini (2012), entrevistou 32 estudantes dos cursos de graduação em Administração de Porto Alegre e da região metropolitana. $O$ estudo baseia-se apenas na inserção do profissional estudante de Administração a partir da experiência de estágio. Salienta-se, porém, que este trabalho não busca classificar o tipo de experiência profissional obtida durante a graduação dos acadêmicos entrevistados. $O$ estudo mostra que os acadêmicos relatam que o curso, na maioria das vezes, possibilita maior interação e complementação do aprendizado da teoria, além de consolidar competências da área de atividade, e ainda explorar ramos específicos da profissão. Mostra ainda que os estudantes buscam responsabilidades que thes permitam acelerar seu desenvolvimento profissional, almejando alcançar o máximo de aprendizado dentro da organização e, quando esta não the proporcionar mais crescimento, buscam outra empresa que o faça. Para alguns estudantes, a busca da prática profissional durante a graduação subsidiará conhecimentos práticos no mercado de trabalho para a abertura de seu próprio negócio.

Sob esta ótica, Escrivão Filho e Ribeiro (2008) ressaltam que é muito comum, que, ao exercerem funções em diferentes áreas de uma empresa ou em várias empresas de diversos setores, os administradores acabem iniciando seu próprio empreendimento. A necessidade de dar continuidade aos estudos após a graduação apareceu em três entrevistados que iniciaram o mestrado logo ao término da graduação. Para Oliveira e Piccinini (2012), a opção por um curso de pós-graduação pode surgir pelo fato de os egressos não conseguirem definir seus objetivos 
pessoais durante a graduação ou por possibilitar um caminho alternativo ao da empresa.

Ainda nessa perspectiva, Neri (2005) revela, na pesquisa intitulada "Retorno da Educação ao Mercado de Trabalho", que indivíduos com pós-graduação são mais bem sucedidos do que aqueles que possuem apenas a graduação. A pesquisa foi realizada em nível nacional a partir de microdados do Censo 2000 do IBGE, e analisou 80 níveis educacionais, cruzando diversas informações para a obtenção dos resultados, tais como: idade, sexo, nível de ensino, curso, carga horária de trabalho, salário, entre outros. Nesse estudo, o curso de graduação em Administração aparece em 24ำ lugar no ranking quanto ao salário, com um valor médio de $\mathrm{R} \$ 4.006$, porém, quando o indivíduo possui Mestrado ou Doutorado em Administração, esse se encontra em $2^{\circ}$ lugar, com uma média salarial de $\mathrm{R} \$ 8.012$, perdendo apenas para Mestrados e Doutorados em Medicina. O ranking mencionado leva em consideração mais de uma fonte de trabalho, pois quando se limita a uma fonte principal de trabalho, o ranking se modifica, em que a primeira situação cai para $40^{\circ}$ lugar, com média salarial de $R \$ 2.386$, e a segunda para $4^{\circ}$ lugar, com média salarial de $\mathrm{R} \$ 5.210$. O estudo informa salários com base em preços do ano de 2005. A atualização de valores pode ser visualizada no Quadro 1, conforme Índice Geral de Preços - Disponibilidade Interna (IGP-DI) da Fundação Getúlio Vargas, calculado através de software disponibilizado pela Fundação e Economia e Estatística do Rio Grande do Sul - FEE.

\begin{tabular}{|c|c|c|}
\hline Ranking & Salário 2005 & Salário 2012 \\
\hline Mestrado / Doutorado em Administração $2^{\circ}$ lugar & $\mathrm{R} \$ 8.012$ & $\mathrm{R} \$ 10.976$ \\
\hline Mestrado / Doutorado em Administração 4ㅇ lugar & $\mathrm{R} \$ 5.210$ & $\mathrm{R} \$ 7.137$ \\
\hline Graduação Administração 24ํㅣㅁ luar & $\mathrm{R} \$ 4.006$ & $\mathrm{R} \$ 5.488$ \\
\hline Graduação Administração 40ำ lugar & $\mathrm{R} \$ 2.386$ & $\mathrm{R} \$ 3.268$ \\
\hline
\end{tabular}

Quadro 1 - Atualização de Salários 2005 - 2012

Fonte: Fundação de Economia e Estatística (2012)

A questão do reflexo da educação no mercado de trabalho estudada por Neri (2005) mostra ainda que há uma relação direta entre a remuneração e o nível de ensino dos indivíduos. Além disso, revela que indivíduos com graduação em 
Administração possuem salário maior do que aqueles que nunca frequentaram ensino superior.

\section{Metodologia}

Para a realização desta pesquisa, utilizou-se o método dedutivo, com abordagem quantitativa, com a finalidade exploratória e descritiva. Seu desenvolvimento deu-se em caráter bibliográfico, através de averiguação de livros, revistas e mídias eletrônicas acerca de autores que versam sobre empregabilidade, mercado de trabalho, organizações, administração e ensino superior. Possui, ainda, caráter documental, pois devido à aplicação do estudo de caso, para maior profundidade e detalhamento, foram consultados documentos de ordem privada das Faculdades Integradas de Taquara. Realizou-se a aplicação de questionário nos meses de agosto e setembro de 2012.

Através da população formada pelos acadêmicos egressos do curso de Administração das Faculdades Integradas de Taquara, chegou-se ao universo de 198 sujeitos formados no período entre 2007 e 2011 e residentes no Vale do Paranhana. Utilizou-se a técnica de amostragem não probabilística, com escolha aleatória simples. Para tanto, foram selecionados $25 \%$ do número egressos de cada ano. Portanto, a amostra foi composta por 50 sujeitos.

A coleta de dados da presente pesquisa foi efetuada através de questionário estruturado e fechado composto por dez perguntas, sendo sete de ordem de dicotomia e três de múltipla escolha. A aplicação do questionário deu-se por método eletrônico, uma vez que um link de acesso on-line ao questionário foi enviado aos respondentes via e-mail.

\section{Análise dos resultados}

Da amostra de 50 sujeitos, obteve-se retorno de 34 respondentes do questionário, que buscou informações acerca de empregabilidade dos egressos do 
curso de Administração das Faculdades Integradas de Taquara, formados no período 2007-2011, residentes no Vale do Paranhana.

A partir da primeira questão, foi possível constatar que a maioria, 82\%, num total de 28 respondentes, permanece atuando no Vale do Paranhana após o término da graduação em Administração.

$\mathrm{Na}$ segunda questão abordada, verificou-se que 53\%, representados por 18 respondentes, não trabalham mais na mesma empresa em que trabalhavam antes de se formarem, mostrando que há rotatividade desses egressos no mercado de trabalho. Verificou-se, também, que todos os respondentes possuíam alguma fonte de trabalho durante o curso de Administração. Em continuidade à questão anterior, a terceira questão mostra que, dos 16 respondentes que continuam trabalhando na mesma empresa, 11 receberam mais responsabilidades após se formarem no curso de Administração.

$\mathrm{Na}$ quarta questão, as respostas mostraram-se totalmente balanceadas, uma vez que exatamente metade dos sujeitos, equivalente a 17, respondeu que possui mais de uma fonte de trabalho, ficando a outra metade respondente com uma única fonte de trabalho.

A questão de número 5 mostra que há, sim, sujeitos com negócio próprio, apesar de minoria, em um total de 8 , equivalente a $24 \%$ do total da amostra.

A partir da sexta questão, foi possível verificar que a maioria dos sujeitos, num total de 22, está conseguindo aplicar os conhecimentos adquiridos ao longo do curso de Administração na vida profissional, seguido por 11 sujeitos que estão conseguindo aplicá-los em parte. Por fim, apenas 1 sujeito respondente não está conseguindo aplicar seus conhecimentos acadêmicos em seu atual trabalho.

As questões 7 e 8, que possuem foco salarial antes e depois da graduação, apontam que há uma visível migração das faixas 1, 2 e 3, que compreendem salários de $R \$ 500,00$ a $R \$ 1.500,00, R \$ 1.600,00$ a $R \$ 2.600,00$ e $R \$ 2.700,00$ a $R \$ 3.700,00$, respectivamente, durante a graduação, para a faixa 4 , que abrange salários de $R \$ 3.800,00$ a $R \$ 4.800,00$ e salários acima de $R \$ 4.800,00$ após a formação no curso de Administração.

A partir da comparação dos dados obtidos, foi possível constatar que houve mudança de faixa salarial para 26 sujeitos, equivalente a $76 \%$ dos respondentes. 
Destes, 21 pularam uma faixa salarial, e 5 pularam dias faixas salariais. Entre os 8 sujeitos restantes, 4 permaneceram na mesma faixa salarial desde que se formaram no curso de Administração, e os outros 4 já possuíam salário acima de $R \$ 4.800$, logo não foi possível avaliar se houve mudança de faixa salarial desses sujeitos após a formação no curso de Administração.

Quando comparados com a média nacional levantada por Neri (2005) para apenas uma fonte de trabalho, dos 17 respondentes, 14 sujeitos, equivalente a $82 \%$ destes, encontram-se acima da média. Seguidos por dois sujeitos, representando $12 \%$, encontram-se dentro da média, e apenas um sujeito encontra-se abaixo da média, representando $6 \%$ desse total.

Quanto aos outros 17 respondentes, com mais de uma fonte de trabalho, 7 sujeitos, correspondentes a $41 \%$, encontram-se abaixo da média, e 10 sujeitos, 59\% do total, encontram-se dentro da média. Salienta-se que, destes 10 sujeitos, não foi possível avaliar se estavam acima da média, pois a pesquisa não fixou teto na opção de ganhos acima de $R \$ 4.800,00$; para tanto, considerou-se estes dentro da média. Constatou-se, ainda, que todos os 34 sujeitos respondentes possuem trabalho remunerado atualmente, portanto pode-se afirmar que o índice de desemprego é nulo.

A questão 9 mostra que a maioria dos sujeitos, num total de 26, representando $76 \%$ dos respondentes, avalia que as empresas do Vale do Paranhana oferecem oportunidades de trabalho para graduados no curso de Administração.

A última questão aponta a procura por cursos de especialização após a formação no curso de Administração. Nove sujeitos, equivalentes a $26 \%$ do total de respondentes, informaram ter dado continuidade aos estudos.

\section{Conclusões}

A partir da análise dos dados obtidos através da aplicação do questionário sobre empregabilidade, é possível afirmar que os egressos, em sua grande maioria, equivalente a $82 \%$, encontram-se remunerados acima da média salarial nacional publicada no estudo de Neri (2005), quando considerada apenas uma fonte de trabalho. Quando considerada mais de uma fonte de trabalho, a maioria dos 
egressos, representados por 59\%, encontra-se dentro da média salarial nacional. Porém, salienta-se que não foi possível constatar egressos com remuneração acima da média para essa última análise, pois estes informaram remuneração dentro da última faixa disponibilizada no questionário, em que não houve delimitação de teto. Apesar não ser possível afirmar que há uma relação direta da influência do curso de Administração na remuneração dos egressos, é possível constatar que $76 \%$ tiveram aumento salarial após se formarem. Registre-se o fato de que $11 \%$ já possuíam a remuneração máxima disponibilizada no questionário, não podendo ser avaliados.

O resultado apontado pelo estudo de Neri (2005), que mostra que indivíduos com mais de uma fonte de emprego são mais bem sucedidos financeiramente, não se aplica aos egressos pesquisados, pois alguns que responderam possuir apenas uma fonte de trabalho, às vezes, ganhavam mais do que aqueles que possuíam mais de uma fonte e vice-versa. Porém conclui-se que metade desses atende ao novo formato de empregabilidade proposto por Minarelli (2010), segundo o qual a partir das mudanças globais e consequentes mudanças organizacionais, o emprego fixo não é mais uma forma de segurança como antigamente e que, para se manter no mercado de trabalho atual, é fundamental a busca por formas alternativas de emprego.

O fato de $50 \%$ dos egressos não se encontrarem trabalhando no mesmo local após a formação no curso de Administração vem ao encontro do estudo de Oliveira e Piccinini (2012), que apontou que estudantes do curso de Administração buscam responsabilidades durante a graduação que thes permitam acelerar seu desenvolvimento profissional dentro de uma organização e, quando esta não lhes proporciona mais crescimento, buscam outra empresa que o faça. Esse dado também foi comprovado entre os egressos que permanecem trabalhando na mesma empresa, pois, destes, 69\% receberam mais responsabilidades após se formarem.

Esse resultado aponta também que $50 \%$ de egressos que não trabalham mais no mesmo local enquadram-se no desenvolvimento econômico proposto por Chahad et al. (1998), que sugerem que o incremento da economia tende à rotatividade dos trabalhadores entre empresas na busca por maiores salários. Além disso, relacionase com Minarelli (2010), que sugere que a busca por conhecimento permite ao trabalhador o poder de escolha de sua forma de emprego. 
Verificou-se a presença da iniciativa pela abertura de um próprio negócio, uma vez que $24 \%$ desses informaram possuir negócio próprio, coincidindo com o estudo de Oliveira e Piccinini (2012), que constatou que, para alguns estudantes, a busca da prática profissional durante a graduação subsidia conhecimentos para a abertura do próprio negócio. Esse fato também é levantado por Escrivão Filho (2008), que ressalta que é muito comum administradores que, ao exercerem variadas funções e passarem por diversos setores, acabem iniciando seu próprio empreendimento. Ficam comprovadas as proposições acima neste estudo, uma vez que, dos 8 egressos que responderam possuir negócio próprio, 5 não trabalham na mesma empresa após a formação no curso de Administração, logo não possuíam negócio próprio durante a graduação.

O estudo de Oliveira e Piccinini (2012) constatou a necessidade de dar continuidade aos estudos após a graduação em 3 indivíduos, de seus 32 (trinta e dois) entrevistados, equivalente a $9 \%$. Com base nesse levantamento, pode-se convir que bom número de egressos desta pesquisa optou por dar continuidade aos estudos, ingressando em um curso de especialização, em número de 9 , quantidade três vezes maior que a do estudo citado, equivalente a $26 \%$. O estudo de Oliveira e Piccinini (2012) sugere que a opção por um curso de pós-graduação pode surgir pelo fato de os egressos não conseguirem definir seus objetivos pessoais durante a graduação ou por possibilitar um caminho alternativo ao da empresa. Nessa perspectiva, o fato de a minoria dos egressos iniciarem um curso de especialização pode se dar pelo motivo de que a maioria destes, $65 \%$, está conseguindo aplicar os conhecimentos adquiridos no curso de Administração.

É possível afirmar que o mercado de trabalho do Vale do Paranhana possui boas oportunidades de trabalho, pelo fato de que a maioria dos egressos, representando $76 \%$ do total, assim o avaliou. Além disso, $82 \%$ dos egressos continuam atuando na região.

Por fim, os egressos, em sua maioria, apresentam remuneração acima da média nacional, apresentam-se bem qualificados por possuírem a capacidade de optarem pela forma de emprego, diversificando as empresas em que atuam, inclusive mostrando iniciativa pela abertura de seu próprio negócio, e ainda possuindo interesse em dar seguimento aos estudos, na busca contínua por 
conhecimento. Dessa forma, o resultado da pesquisa mostra-se satisfatório quanto à empregabilidade dos egressos do curso de Administração das Faculdades Integradas de Taquara, formados no período 2007-2011, residentes no Vale do Paranhana, apontando resultados positivos.

Salienta-se que este estudo avalia de forma geral a empregabilidade dos egressos, não apresentando nenhuma elucidação acerca de estudos que versem sobre o que seria um salário ideal e satisfatório, pois apenas se efetuo um comparativo de acordo com o estudo de Neri (2005), para avaliar se estes se encontram remunerados de acordo com a média nacional.

Na presente pesquisa, não foram considerados dados como idade, tempo de trabalho e porte da empresa para avaliação da empregabilidade dos acadêmicos egressos do curso de Administração das Faculdades Integradas de Taquara, uma vez que essas informações trariam maior abrangência e profundidade à pesquisa, podendo se tornar objetos para estudos futuros.

\section{Referências}

AGENDA 2020. Agenda 2020 apresenta características do Vale do Paranhana. Disponível em: http://wp.clicrbs.com.br/gauchadebates/2011/05/12/ agenda-2020apresenta-caracteristicas-do-vale-do-paranhana>. Acesso em: 3 mar. 2012.

ALMEIDA, Marcus Garcia de. Pedagogia empresarial: Saberes, Práticas e Referências. Rio de Janeiro: Brasport, 2006.

ALONSO, Félix Ruiz; LÓPEZ, Francisco Granizo; CASTRUCCI, Plínio de Lauro. Curso de ética em administração. São Paulo: Atlas, 2006.

BANDURA. A. Self-efficacy: The exercise of control. New York: Freeman, 1997. CONSELHO FEDERAL DE ADMINISTRAÇÃO. Manual de Responsabilidade Técnica do Administrador. Resolução Normativa CFA № 337, de 4 de dez. de 2006.

CAMPOS, Keli Cristina de Lara. Construção de uma escala de empregabilidade: definições e variáveis psicológicas. Campinas: Estudos de Psicologia, 2011. Disponível em: <http://www.scielo.br/scielo.php? script=sci_arttext\&pid=S0103166X2011000100005\&lng=en\&nrm=iso>. Acesso em: 9 jun. 2012.

CASAS, Alexandre Luzzi Las et al. Novos Rumos da Administração. Rio de Janeiro: Vozes, 1999. 
CHAHAD, José Paulo Zeetano et al. Manual de Economia. 3. ed. São Paulo: Saraiva, 1998.

CHIAVENATO, Idalberto. Recursos Humanos - o capital humano das organizações. 8. ed. São Paulo: Atlas, 2008.

ESCRIVAO FILHO, Edmundo; RIBEIRO, Luis Roberto de Camargo. Inovando no ensino de administração: uma experiência com a aprendizagem baseada em problemas (PBL). Rio de Janeiro: Caderno EBAPE.BR, 2008 . Disponível em: $<$ http://www.scielo.br/scielo.php?script=sci_arttext\&pid=S1679-395120080 00500004\&lng=en\&nrm=iso >. Acesso em: 1 set. 2012.

FACULDADES INTEGRADAS DE TAQUARA. Histórico Institucional. Disponível em: $<w w w . f a c c a t . b r / i n s t i t u c i o n a l>$ Acesso em: 10 mar. 2012

FIORELLI, José Osmir. Psicologia para administradores: integrando teoria e prática. 3. ed. São Paulo: Atlas, 2003.

FUNDAÇÃO DE ECONOMIA E ESTATÍSTICA. FEE. PIB-RS e População-RS. 2009. Disponível em: <http://www.fee.tche.br/sitefee/pt/content/estatisticas>. Acesso em: 20 abr. 2012.

. Atualização de Valores. Disponível em: <http://www.fee.tche.br/ sitefee/ pt/content/servicos/pg_atualizacao_valores.php>. Acesso em: 8 set. 2012.

HELAL, Diogo Henrique; ROCHA, Maíra. O discurso da empregabilidade: o que pensam a academia e o mundo empresarial. Caderno. Rio de Janeiro EBAPE.BR, 2011. Disponível em: <http://www.scielo.br/scielo.php?script=sci_arttext\&pid= S1679-39512011000100009\&lng=en\&nrm=iso >. Acesso em: 3 set. 2012.

KOHLRAUSCH, Marlin José. Você está preparado? Como sair na frente em um mercado em constante transformação. São Paulo: Gente, 2004.

LACOMBE, Francisco José Masset; HEILBORN, Gilberto Luiz José. Administração Princípios e Tendências. 2. ed. São Paulo: Saraiva, 2008.

LEMOS, Ana Heloísa da Costa; PINTO, Mario Couto Soares. Empregabilidade dos administradores: quais os perfis profissionais demandados pelas empresas?

Cadernos. Rio de Janeiro: EBAPE.BR, 2008. Disponível em: <http://www.scielo.br/ scielo.php?script=sci_arttext\&pid=S1679-39512008000400010\&lng=en\&nrm=iso $>$. Acesso em: 2 set. 2012.

LIMA, Solange Moreira Dias de. O perfil do administrador do presente, face às novas tecnologias da informação. 2002. Disponível em:

<www.portaldomarketing.com.br/artigos>. Acesso em: 12 set. 2012.

MARQUES, Ana Paula. "Novas" legitimidades de segmentação do mercado de trabalho de jovens diplomados. Braga: Rev. Port. de Educação, 2009. Disponível 
em: <http://www.scielo.gpeari.mctes.pt/scielo.php?script=sci_arttext \&pid=S087191872009000200005\&lng=pt\&nrm=iso >. Acesso em 19 ago. 2012.

MINARELLI, José Augusto. Empregabilidade - Como entrar, permanecer e progredir no mercado de trabalho. 25. ed. São Paulo: Gente, 2010.

NÉRI, Marcelo. Retornos da educação no mercado de trabalho. Rio de Janeiro: FGV, 2005. Disponível em: <http://www.fgv.br>. Acesso em: 30 jun. 2012.

OLIVEIRA, Sidinei Rocha de; PICCININI, Valmiria Carolina. Uma análise sobre a inserção profissional de estudantes de administração no Brasil. São Paulo: RAM, Rev. Adm. Mackenzie, 2012. Disponível em: <http://www.scielo.br/scielo.php?script= sci arttext\&pid=S1678-9712012000200003\&lng=en\&nrm=iso>. Acesso em: 10 ago. 2012.

Mercado de trabalho: múltiplos (des)entendimentos. Rio de Janeiro: Rev. Adm. Pública, 2011. Disponível em: <http://www.scielo.br/scielo.php? script=sci_arttext\&pid $=$ S0034-76122011000500012\&lng=en\&nrm=iso $>$. Acesso em: 10 ag. 2012.

PASTORE, J. Tecnologia e Emprego. São Paulo: CNI, 1998. (Coleção José Ermírio de Moraes).

PROBST, Gilbert; RAUB, Steffen; ROMHARDT, Kai. Gestão do Conhecimento: os elementos construtivos do sucesso. Porto Alegre: Bookman, 2002.

STEWART, Thomas A. Capital Intelectual: a nova vantagem competitiva das empresas. 3. ed. Rio de Janeiro: Campus, 1998. 